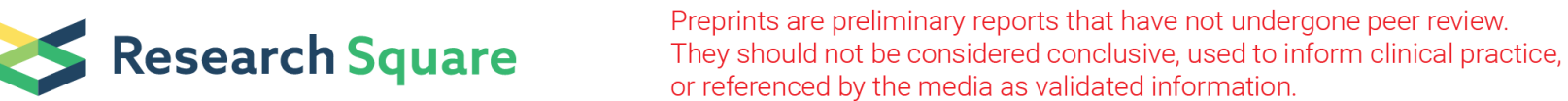

\section{Legacy Effects of Extreme Drought on the Belowground Bud Bank of Bunchgrass and Rhizomatous Steppe Communities in Inner Mongolia}

Wentao Luo ( $\square$ wentaoluo@iae.ac.cn )

IAE,CAS https://orcid.org/0000-0002-9543-1123

Jianqiang Qian

Henan Agricultural University

Ziyue Guo

Henan Agricultural University

Taofeek O. Muraina

Oyo State College of Agriculture and Technology

Niwu Te

CAS IAE: Institute of Applied Ecology Chinese Academy of Sciences

Robert J. Griffin-Nolan

Syracuse University

Lin Song

CAS IAE: Institute of Applied Ecology Chinese Academy of Sciences

Chong Xu

Chinese Academy of Agricultural Sciences

Qiang Yu

Chinese Academy of Agricultural Sciences

Dan Liu

Henan Agricultural University

\section{Research Article}

Keywords: climate change, grassland restoration, meristem limitation, population regeneration, vegetative reproduction

Posted Date: June 28th, 2021

DOl: https://doi.org/10.21203/rs.3.rs-586057/v1 
License: (c) (i) This work is licensed under a Creative Commons Attribution 4.0 International License. Read Full License 


\section{Abstract}

Belowground bud banks play a crucial role in plant population regeneration, community dynamics and ecosystem functions in response to environmental change and disturbance. In mesic grasslands, belowground bud banks are largely resistant to short-term drought. The sensitivity of belowground bud banks to long-term extreme drought in semiarid steppes is less understood. Here, we investigated the legacy effects of a 4-year experimental drought (i.e., $66 \%$ reduction in growing season precipitation) on belowground bud density, aboveground shoot density and their relationship (represented by the meristem limitation index-MLI) in two temperate semiarid steppes with different dominated plant growth forms (i.e., bunchgrass vs. rhizomatous grass). Measurements were made during the first recovery year following drought; thus, we reported the legacy effects of drought on belowground bud bank. Results showed that at community level the densities of both belowground buds and aboveground shoots decreased while there was no change in MLI. However, drought had no significant influences on belowground buds, aboveground shoots and MLI of the dominant plant growth form. The legacy effects of drought were largely dependent on plant community type and growth form. Specifically, due to their cluster/phalanx clonal growth, bunchgrasses and communities they dominated were characterized by greater meristem limitation compared with rhizomatous grasses. Our study implies that integrating belowground bud bank demography into the predictive model of community dynamics and ecosystem functions in response to climate change should be considered to understand the differing responses among community type and dominant plant groups.

\section{Introduction}

Climate change is expected to increase rainfall variability as well as the frequency of extreme drought (Min et al. 2011; Smith 2011; IPCC 2013; Hoover et al. 2016), with some regions already experiencing such changes (Williams et al. 2020). In grasslands, drought can alter community composition and structure, decrease aboveground net primary productivity (ANPP), and shift biomass allocation patterns (Frank 2007; Evans et al. 2011; Hoover et al. 2014; Meng et al. 2019; Zhang et al. 2019; Zhao et al. 2020); however, grasslands are also highly resilient ecosystems. Previous studies suggested that ANPP can completely recover to pre-drought levels within one year after drought (Hoover et al. 2014; Wilcox et al. 2020). While legacy effects of drought are often negative (Sala et al. 2012), some grasslands are more productive than expected one year after drought (Griffin-Nolan et al. 2018). Furthermore, a recent metaanalysis suggested that resilience, rather than resistance, maintained grassland ecosystem productivity following extreme drought (Stuart-Haëntjens et al. 2018). Population regeneration is critical for the resistance and/or resilience of grassland vegetation to climate extremes (Stampfli and Zeiter 2004), and is likely linked to belowground bud bank dynamics (VanderWeide et al. 2014).

Plants can regenerate sexually through the production of seeds, or asexually via growth from belowground meristems (Harper 1977; Ott et al. 2019). Belowground bud banks plays a key role in regulating population regeneration, community dynamics and ecosystem functioning in perennial grasslands following disturbances (e.g., fire and grazing), environmental changes (e.g., variations in 
precipitation) and changes in nutrient availability (Benson et al. 2004; Benson and Hartnett 2006; Dalgleish and Hartnett 2006; Dalgleish and Hartnett 2009; VanderWeide et al. 2014; Qian et al. 2017a, 2017b; Ma et al. 2019; Ott et al. 2019). This suggests that belowground buds, as the primary source of tiller/ramet production in many grassland communities, could contribute to rapid recovery following drought (VanderWeide et al. 2014; Ott et al. 2019). Past studies have shown that belowground bud bank density increases along a precipitation gradient (Dalgleish and Hartnett 2006; Qian et al. 2017a) and is insensitive to short-term (2-year) drought in mesic $\mathrm{C}_{4}$ grasslands (VanderWeide et al. 2014). Less is known about how long-term extreme drought influence bud bank dynamics of more arid grassland communities.

Here, we studied the legacy effects of an experimental extreme drought (66\% reduction in growing season precipitation) on belowground bud density, aboveground shoot density and meristem limitation index (MLI) in two semiarid steppes. These two sites share relatively similar climate, but one is dominated by a rhizomatous grass (Leymus chinensis) while the other is dominated by a bunchgrass (Stipa grandis) (Bai et al. 2004). Previous study has showed a negative effect of extreme drought on ecosystem functioning (Luo et al. 2021), and the present work is assessing the recovery of aboveground shoot density following a long-term drought and its relationships with belowground bud density. We hypothesized that both belowground bud density and aboveground shoot density would recover quickly during the first recovery year following the long-term extreme drought (VanderWeide et al. 2014; Ott et al. 2019). We also hypothesized that the legacy effects of experimental drought on bud and shoot densities as well as their relationships would vary with community types (L. chinensis vs. S. grandis dominated community) due to their difference in the traits of the dominant grass species.

\section{Materials And Methods}

\section{Study sites}

This study was conducted at two sites within the Inner Mongolia Grassland Ecosystem Research Station $\left(116^{\circ} 33^{\prime} \mathrm{E}, 43^{\circ} 32^{\prime} \mathrm{N}\right)$ in Northern China. The two sites are characterized as temperate semi-arid steppe and share similar climatic conditions. The long-term (1982-2018) mean annual temperature and mean annual precipitation (MAP) are $1.9^{\circ} \mathrm{C}$ and $333 \mathrm{~mm}$, respectively. About $72 \%$ of MAP (i.e., $242 \mathrm{~mm}$ ) falls during the growing season (May through August). The major soil types of this region are calcic chestnuts and calcic chernozems (Luo et al. 2018).

The two sites differ in species composition with one being dominated by a rhizomatous grass (Leymus chinensis) and the other by a bunchgrass (Stipa grandis). Importantly, each of these species also occur in the community where they are not dominant, but at lower abundance. The rhizomatous grass and bunchgrass communities have been fenced to exclude large ungulate herbivores since 1999 and 1979, respectively (Bai et al. 2004). Both communities reach peak productivity (ANPP of about $193 \mathrm{~g} \mathrm{~m}^{-2}$ for the L. chinensis dominated community, and $217 \mathrm{~g} \mathrm{~m}^{-2}$ for the $S$. grandis dominated community) in midAugust (Kang et al. 2007). 


\section{Drought experiment}

These sites are part of the Extreme Drought in Grassland Experiment (EDGE) in China (http://edge.biology.colostate.edu/). Beginning in 2015, we imposed drought treatments using rainfall exclusion shelters that blocked $66 \%$ of growing season precipitation (GSP). A randomized complete block design with six plots $(6 \mathrm{~m} \times 6 \mathrm{~m})$ each for control (i.e., ambient) and drought treatments at each site. We oriented plots such that each plot was separated from neighboring plots by at least $2 \mathrm{~m}$. Rainfall exclusion shelters were installed in May of 2015 and removed them at the end of August each year for four consecutive years (2015-2018). Plots were hydrologically isolated from the surrounding soil matrix using aluminum flashing buried to a depth of $1 \mathrm{~m}$. To minimize edge effects associated with the rainout shelter, a $1 \mathrm{~m}$ external buffer zone was established under each shelter. To allow for rapid runoff of intercepted precipitation, the shelters were designed with a slight slope towards a subtle topographic gradient. To reduce greenhouse effects and allow for surface air flow, the roofs were raised so that the lowest section of each shelter was $2 \mathrm{~m}$ aboveground. Previous measurements indicated that these shelters allowed $>90 \%$ penetration of photosynthetically active radiation (Luo et al. 2019, 2021; Muraina et al. 2021).

The average annual precipitation and GSP during the four-year experimental period were $312 \pm 25 \mathrm{~mm}$ and $199 \pm 31 \mathrm{~mm}$, respectively. Based on the estimated long-term (1972-2018) normal distribution of precipitation for the two sites, we effectively imposed an extreme drought during this 4-year period (i.e., precipitation below the $5^{\text {th }}$ percentile of the historical record). For more details on drought treatment infrastructure and effectiveness, see Luo et al., 2021. The precipitation in the months was near normal during the recovery period (2019).

\section{Sampling and investigation}

To assess drought impacts on bud bank dynamics, the belowground bud bank and its corresponding aboveground vegetation were investigated in late July 2019 (the first recovery year following 4-year experimental drought). As most buds in this steppe are located in shallow soil profiles $(0-30 \mathrm{~cm})$, all belowground parts were excavated to a depth of $30 \mathrm{~cm}$ within a $30 \mathrm{~cm} \times 30 \mathrm{~cm}$ quadrat placed in each experimental plot (Qian et al. 2017a, 2017b). The connection between belowground- and aboveground plant parts was kept intact to accurately identify the buds of different species. Samples were stored in plastic bags, taken back to lab and processed them within one week. Following the procedures of Qian et al. (2017a, 2021), the sampled belowground buds were categorized into four bud types: (1) tiller buds (axillary buds at the shoot base of caespitose and rhizomatous grasses), (2) rhizome buds (axillary buds and apical buds on hypogeogenous rhizomes sensu Klimešová and Klimeš (2008), (3) bulb buds (meristems wrapped in the swollen leaf base or scale leaf of bulb species) and (4) dicot buds (buds on belowground parts of dicotyledonous herbs). Given that different bud types differ in their morphological characteristics, the shoot and bulb bases need to be dissected to count tiller buds and bulb buds while rhizome- and dicot buds were counted without dissection. Plant species were sorted into grasses (with tiller buds and rhizome buds) and forbs (with bulb buds and dicot buds). To effectively compare the 
recovery of the two dominant grasses (bunch grass vs rhizomatous grass) following the extreme drought, the number of aboveground shoots (tillers or ramet) were counted within each quadrat which buds were sampled and then classified into two plant groups.

\section{Metrics and statistical analysis}

Given that grasses accounted for the $90.75 \%$ of the total bud density and $95.77 \%$ of total shoot density in the two grassland communities, we mainly focused on grass responses (i.e., bunchgrass vs rhizomatous grass). The number of buds and shoots recorded in each quadrat was regarded as the measures of belowground bud and aboveground shoot densities (per square meter), respectively. The meristem limitation index $(\mathrm{MLI})$, a measure of the degree of limitation that belowground buds imposed on aboveground population recruitment/regeneration in perennial grasslands, was calculated as the ratio of belowground bud density to aboveground shoot density (Benson et al. 2004).

We assessed the legacy effect of extreme drought on total belowground bud density, total aboveground shoot density, and total MLI as well as on those of dominant growth forms (bunchgrass vs rhizomatous grass) across the two steppes and whether the drought legacy effects vary with community type by conducting a mixed-model analysis of variance (ANOVA) with drought treatment and community as fixed factors and block as random factor. When interactive effects of drought treatment and community were marginally significant $(P<0.1)$, the mixed model analysis of variance was separately applied for each community with drought treatment as fixed factor and block as random factor.

Before statistical analysis, we used Shapiro-Wilk and Levene's tests confirm all data were normally distributed and had equal variance. Original data were used in our statistical analyses without transformation. All statistical analyses were carried out using the $n$ lme package in $\mathrm{R}(\mathrm{R}$ i386 3.1.1).

Table 1 Results of mixed-effects ANOVA for the effects of drought legacy and community type on the belowground bud density, aboveground shoot density, and meristem limitation index of the whole plant community and two dominant growth forms (bunchgrass and rhizomatous grass). 
Drought legacy (D) Community type (C) D×C

\begin{tabular}{lllll}
\hline \multirow{2}{*}{ Total } & Bud density & $\mathbf{0 . 0 7 7}$ & $<0.001$ & 0.501 \\
\cline { 2 - 5 } & Shoot density & $\mathbf{0 . 0 7 6}$ & 0.227 & $\mathbf{0 . 0 6 9}$ \\
\cline { 2 - 5 } & Limitation index & 0.205 & $<\mathbf{0 . 0 0 1}$ & 0.126 \\
\hline \multirow{2}{*}{ Bunchgrass } & Bud density & 0.418 & $\mathbf{0 . 0 0 4}$ & 0.78 \\
\cline { 2 - 5 } & Shoot density & 0.222 & 0.789 & $\mathbf{0 . 0 6 9}$ \\
\cline { 2 - 5 } & Limitation index & 0.295 & $<\mathbf{0 . 0 0 1}$ & 0.241 \\
\hline \multirow{2}{*}{ Rhizomatous } & Bud density & 0.136 & $<0.001$ & 0.1162 \\
\cline { 2 - 5 } grass & Shoot density & 0.194 & $\mathbf{0 . 0 0 4}$ & 0.619 \\
\cline { 2 - 5 } & Limitation index & 0.866 & 0.197 & 0.525
\end{tabular}

\section{Results}

The total bud density and MLI in the L. chinensis community were significantly higher than those in the $S$. grandis community both under the control (ambient precipitation) and drought treatment, while there were no significant differences in the total shoot density between the two plant communities (Table 1 and Fig. 1). The legacy of the 4-year drought marginally reduced total belowground bud and shoot densities in each grassland communities $(P<0.1)$, but did not alter total MLI (Fig. 1 and Table 1). The drought treatment $\times$ community type interaction was marginally significant for the aboveground shoot density $(P<0.1)$, indicating that the recovery of total shoot density following extreme drought differed between the two community types (Table 1 ). Specifically, the total shoot density of the $S$. grandis dominated community was lower in drought plots compared to ambient plots $(P<0.05)$ but was unchanged in the $L$. chinensis dominated community (Fig. 1).

When separated by growth form, the extreme drought treatment had no significant legacy effect on bud densities or MLI of either bunchgrass or rhizomatous grasses across the two grassland communities (Table 1). The drought treatment significantly reduced shoot density of bunchgrasses in the $S$. grandis dominated community (Fig. 2).

Together, the bud densities of grasses (bunchgrass vs rhizomatous grass) in the L. chinensis dominated community was significantly higher than that in the in the $S$. grandis dominated community $(P<0.01)$ while there was no significant difference in shoot densities between the two plant communities. As such, the $\mathrm{MLI}$ in the $L$. chinensis dominated community (MLI=0.74-1.03 under ambient precipitation and $\mathrm{MLI}=0.81-0.91$ under drought treatment) was significantly higher than that in the in the $S$. grandis dominated community (MLI=0.08-0.45 under ambient precipitation and $\mathrm{MLI}=0.09-0.31$ under drought treatment) $(P<0.01)$ (Table 1, Fig. 2). Furthermore, there were no significant differences in the bud density between bunchgrass and rhizomatous grass while the shoot density of bunchgrass was significantly 
higher $(P<0.01)$ than that of rhizomatous grass, which led to a higher MLI of rhizomatous grasses compared with bunchgrasses $(P<0.01)$ (Table 1, Fig. 2).

\section{Discussion}

The potential for vegetation to recover from extreme drought is an important driver of grassland ecosystem dynamics (Stampfli and Zeiter 2004) and is likely limited by the resistance/resilience of belowground bud banks (VanderWeide et al. 2014). We investigated the density of belowground buds and aboveground shoots in two semi-arid steppes one year after a long-term (4-yr) extreme drought (66\% reduction in ambient precipitation). At both sites, we observed reduced belowground bud density in plots that had previously experienced drought. The observed negative legacy effect contradicts previous work in more mesic grasslands where bud density was unchanged following a 2-year drought of similar intensity (VanderWeide et al. 2014). A negative drought legacy effect was also observed aboveground (i.e., shoot density), but only at the site dominated by the bunchgrass, $S$. grandis. However, we did not detect a legacy effect of extreme drought on MLI (i.e., buds per shoot) at either site. This suggests that while extreme drought reduced bud and shoot density, the response potential of these communities to further changes in precipitation was unaltered (Knapp and Smith 2001; Dalgleish and Hartnett 2006).

Belowground bud density tends to decline with increasing aridity, a trend observed in both North America and northern China (Dalgleish and Hartnett 2006; Qian et al. 2017a). While plants in semi-arid communities are often drought tolerant, they also operate near their limit of water stress. Accordingly, ANPP of xeric grasslands is often more sensitive to drought than that of mesic grasslands (Knapp et al. 2015). This may explain why our observed sensitivity of belowground bud density was higher than that reported for more mesic sites (MAP of 333 vs. 880 mm; VanderWeide and Hartnett 2014). Grasses in more mesic areas may allocate more resources to belowground tissue during drought which ensures population regeneration when normal precipitation conditions return, whereas in semiarid environments, short-term extreme drought substantially reduces productivity and subsequent resource allocation belowground.

We also noted significant differences between the two plant communities in belowground bud dynamics. Specifically, the belowground bud density and MLI in the L. chinensis dominated community were significantly higher than those in the $S$. grandis dominated community under both ambient precipitation and drought treatment, which suggests bunchgrass communities may face greater meristem limitation. Thus, the belowground bud bank constrains its response ability to resource pulses and restrict its resistance/resilience to climatic perturbation (Benson et al. 2004; Dalgleish and Hartnett 2006; Qian et al. 2021). This might be attributed to the differences in root systems as $L$. chinensis dominated community has a relatively shallower root system than the $S$. grandis dominated community (Xiao et al. 1995; Wang et al. 2016). Thus, drought could negatively affect belowground buds via higher reductions in soil moisture in surface soil than in deeper soil profile (Schwinning et al. 2005; Hoover et al. 2017). 
Our results also showed that the bud banks of bunchgrass and rhizomatous grass recovered differently after an extreme drought. Bunchgrasses face a greater meristem limitation than rhizomatous grasses due to their clustered. Wang et al. (2019) found that short-term summer drought decreased the bud bank density and shoot production of $L$. chinensis, and consequently constrained both its current and future productivity, but increased the proportion of buds which developed into rhizomes. In combination with our results, this suggests we must consider belowground bud bank demography in predictive models of how drought may alter community dynamics and ecosystem functions.

In conclusion, the density of both belowground buds and aboveground shoots were reduced one year following drought but meristem limitation was unaltered in this temperate semiarid steppe. The legacy effects of extreme drought on belowground bud bank and its relationship with aboveground vegetation depended on plant community type and plant growth forms. Due to the cluster form/phalanx clonal growth, bunchgrass communities face a greater meristem limitation than rhizomatous grass communities. Belowground bud bank dynamics may constrain community responses to climate change and human disturbances, and consequently has important implications on ecosystem function and services.

\section{Declarations}

\section{Acknowledgements}

This study was financially supported by the National Natural Science Foundation of China (41877542, 41501573, 31600443). We thank Drs. Alan K. Knapp, Melinda D. Smith and Scott L. Collins for their helpful comments on Extreme Drought in Grassland Experiment (EDGE) platform.

\section{References}

Bai YF, Han XG, Wu JG, Chen ZZ, Li LH (2004) Ecosystem stability and compensatory effects in the Inner Mongolia grassland. Nature 431:181-184.

Beier C, Beierkuhnlein C, Wohlgemuth T, et al. (2012) Precipitation manipulation experiments-challenges and recommendations for the future. Ecology Letters 15:899-911.

Benson EJ, Hartnett DC (2006) The role of seed and vegetative reproduction in plant recruitment and demography in tallgrass prairie. Plant Ecology 187:163-178.

Benson EJ, Hartnett DC, Mann KH (2004) Belowground bud banks and meristem limitation in tallgrass prairie plant populations. American Journal of Botany 91:416-421.

Carter DL, Vanderweide B, Blair JM (2012) Drought-mediated stem and below-ground bud dynamics in restored grasslands. Applied Vegetation Science 15:470-478. 
Dalgleish HJ, Hartnett DC (2006) Below-ground bud banks increase along a precipitation gradient of the North American Great Plains: a test of the meristem limitation hypothesis. New Phytologist 171:81-89.

Dalgleish HJ, Hartnett DC (2009) The effects of fire frequency and grazing on tallgrass prairie productivity and plant composition are mediated through bud bank demography. Plant Ecology 201:411420.

Evans SE, Byrne KM, Lauenroth WK, Burke IC (2011) Defining the limit to resistance in a drought-tolerant grassland: long-term severe drought significantly reduces the dominant species and increases ruderals. Journal of Ecology 99:1500-1507.

Frank DA (2007) Drought effects on above- and belowground production of a grazed temperate grassland ecosystem. Oecologia 152:131-139.

Griffin-Nolan RJ, Carroll CJ, Denton EM, Johnston MK, Collins SL, Smith MD, Knapp AK (2018) Legacy effects of a regional drought on aboveground net primary production in six central US grasslands. Plant ecology 219(5):505-515.

Harper JL (1977) Population Biology of Plants. Academic Press, New York, USA.

He M, Dijkstra FA (2014) Drought effect on plant nitrogen and phosphorus: a meta-analysis. New Phytologist 204:924-931.

Hoover DL, Duniway MC, Belnap J (2016) Testing the apparent resistance of three dominant plants to chronic drought on the Colorado Plateau. Journal of Ecology 105(1):152-162.

Hoover DL, Knapp AK, Smith MD (2014) Resistance and resilience of a grassland ecosystem to climate extremes. Ecology 95:2646-2656.

IPCC (2013) Climate change 2013: the physical science basis. In: Stocker TF, Qin D, Plattner GK, Tignor M, Allen SK, Boschung J, Nauels A, Xia Y, Bex V, Midgley PM (eds) Contribution of working group I to the fifth assessment report of the intergovernmental panel on climate change. Cambridge University Press, Cambridge.

Kang L, Han XG, Zhang ZB, Sun OJ (2007) Grassland ecosystems in China: review of current knowledge and research advancement. Philosophical Transactions of The Royal Society B Biological Sciences 362(1482):997-1008.

Klimešová J, Klimeš L (2007) Bud banks and their role in vegetative regeneration-A literature review and proposal for simple classification and assessment. Perspectives in Plant Ecology Evolution and Systematics 8:115-129.

Klimešová J, Klimeš L (2008) Clonal growth diversity and bud banks of plants in the Czech flora: an evaluation using the CLO-PLA3 database. Preslia 80:255-275. 
Knapp AK, Smith MD (2001) Variation among biomes in temporal dynamics of aboveground primary production. Science 291(5503):481-484.

Luo WT, Xu C, Ma W, et al. (2018) Effects of extreme drought on plant nutrient uptake and resorption in rhizomatous vs bunchgrass-dominated grasslands. Oecologia 188:1-11.

Luo WT, Zuo X, Griffin-Nolan RJ, Xu C, Ma W, et al. (2019) Long term experimental drought alters community plant trait variation, not trait means, across three semiarid grasslands. Plant and Soil 442:343-353.

Luo WT, Griffin-Nolan RJ, Ma W et al. (2021) Plant traits and soil fertility mediate productivity losses under extreme drought in C3 grasslands. Ecology (accepted).

Ma Q, Qian JQ, Tian L, Liu ZM (2019) Responses of belowground bud bank to disturbance and stress in the sand dune ecosystem. Ecological Indicators 106:105521.

Meng B, Shi BK, Zhong SZ, et al. (2019) Drought sensitivity of aboveground productivity in Leymus chinensis meadow steppe depends on drought timing. Oecologia 191(3):685-696.

Min SK, Zhang X, Zwiers FW, Hegerl GC (2011) Human contribution to more-intense precipitation extremes. Nature 470:378-381.

Muraina TO, Xu C, Yu Q, et al. (2021) Species asynchrony stabilises productivity under extreme drought across Northern China grasslands. Journal of Ecology 109: 1665- 1675.

Ott JP, Klimešová J, Hartnett DC (2019) The ecology and significance of below-ground bud banks in plants. Annals of Botany 123:1099-1118.

Qian JQ, Wang ZW, Klimesova J, et al. (2017a) Differences in below-ground bud bank density and composition along a climatic gradient in the temperate steppe of northern China. Annals of Botany 120:755-764.

Qian JQ, Wang ZW, Liu ZM, Busso CA (2017b) Belowground bud bank responses to grazing intensity in the Inner-Mongolia steppe, China. Land Degradation \& Development 28:822-832.

Qian JQ, Wang ZW, Klimesova J, Lü XT, Zhang CY (2021) Belowground bud bank and its relationship with aboveground vegetation under watering and nitrogen addition in temperate semiarid steppe. Ecological Indicators 125:107520.

Sala OE, Gherardi LA, Reichmann L, Jobbagy E, Peters D (2012) Legacies of precipitation fluctuations on primary production: theory and data synthesis. Philosophical Transactions of the Royal Society B:

Biological Sciences 367(1606):3135-3144. 
Sardans J, Peñuelas J (2015) Potassium: a neglected nutrient in global change. Global Ecology and Biogeography 24:261-275.

Schwinning S, Starr BI, Ehleringer JR (2005) Summer and winter drought in a cold desert ecosystem (Colorado Plateau) part l: effects on soil water and plant water uptake. Journal of Arid Environments 60(4):547-566.

Smith MD (2011) An ecological perspective on extreme climatic events: a synthetic definition and framework to guide future research. Journal of Ecology 99:656-663.

Stampfli A, Zeiter M (2004) Plant regeneration directs changes in grassland composition after extreme drought: a 13-year study in southern Switzerland. Journal of Ecology 92:568-576.

Stuart-Haëntjens E, De Boeck HJ, Lemoine NP, et al. (2018) Mean annual precipitation predicts primary production resistance and resilience to extreme drought. Science of the Total Environment 636:360-366.

VanderWeide BL, Hartnett DC (2015) Belowground bud bank response to grazing under severe short-term drought. Oecologia 178:795-806.

VanderWeide BL, Hartnett DC, Carter DL (2014) Belowground bud banks of tallgrass prairie are insensitive to multi-year, growing-season drought. Ecosphere 5(8):103.

Wang JF, Shi YJ, Ao YN (2019) Summer drought decreases Leymus chinensis productivity through constraining the bud, tiller and shoot production. Journal of Agronomy and Crop Science 205(6):554-561.

Wang RX, Tian YQ, Ouyang SN, Xu XL, Xu FZ, Zhang Y (2016) Nitrogen acquisition strategies used by Leymus chinensis and Stipa grandis in temperate steppes. Biology and Fertility of Soils 52(7):951-961.

Wilcox KR, Koerner SE, Hoover DL, et al. 2020. Rapid recovery of ecosystem function following extreme drought in a South African savanna grassland. Ecology 101(4):e02983.

Williams AP, Cook ER, Smerdon JE, et al. (2020) Large contribution from anthropogenic warming to an emerging North American megadrought. Science 368(6488):314-318.

Xiao XM, Wang YF, Jiang S, Ojima DS, Bonham CD (1995) Interannual variation in the climate and aboveground biomass of Leymus chinensis steppe and Stipa grandis steppe in the Xilin river basin, Inner Mongolia, China. Journal of Arid Environments 31:283-299.

Yahdjian L, Sala OE (2002) A rainout shelter design for intercepting different amounts of rainfall. Oecologia 133:95-101.

Zhang FY., Quan Q, Ma FF (2019) When does extreme drought elicit extreme ecological responses? Journal of Ecology 107(6):2553-2563. 
Zhao AZ, Yu QY, Feng LL, Zhang AB, Pei T (2020) Evaluating the cumulative and time-lag effects of drought on grassland vegetation: A case study in the Chinese Loess Plateau. Journal of Environmental Management 261:110214.

Zhao LP, Wang D, Liang FH, Liu Y, Wu GL (2019) Grazing exclusion promotes grasses functional group dominance via increasing of bud banks in steppe community. Journal of Environmental Management 251:109589.

\section{Figures}

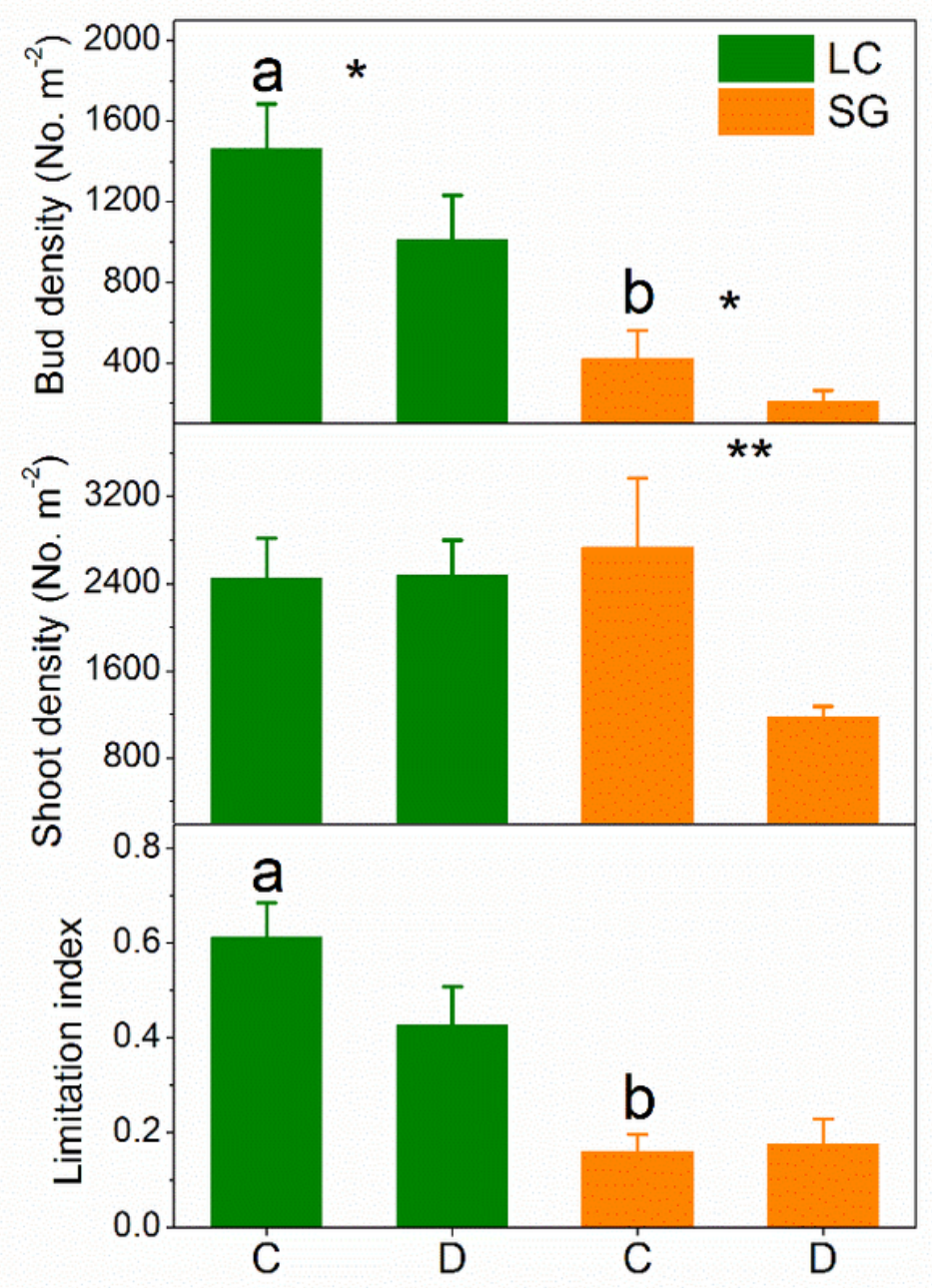

\section{Figure 1}

Effects of drought legacy and community type on total belowground bud density, total aboveground shoot density and the meristem limitation index (MLI) in two plant communities with different dominant species (LC, L. chinensis dominated community; SG, S. grandis dominated community). Each point represents the means with error bars indicating standard errors calculated from replicate plots for each treatment. Different letters indicate significant differences between the L. chinensis and S. grandis dominated at $P<0.05$. Statistical significance of drought legacy effect is depicted ${ }^{*} P<0.1$ and $* * P<0.05$. $C$, 
control (i.e., the ambient precipitation); D, recovery following the drought treatment (i.e., 4-year reduction of $66 \%$ growing season precipitation).
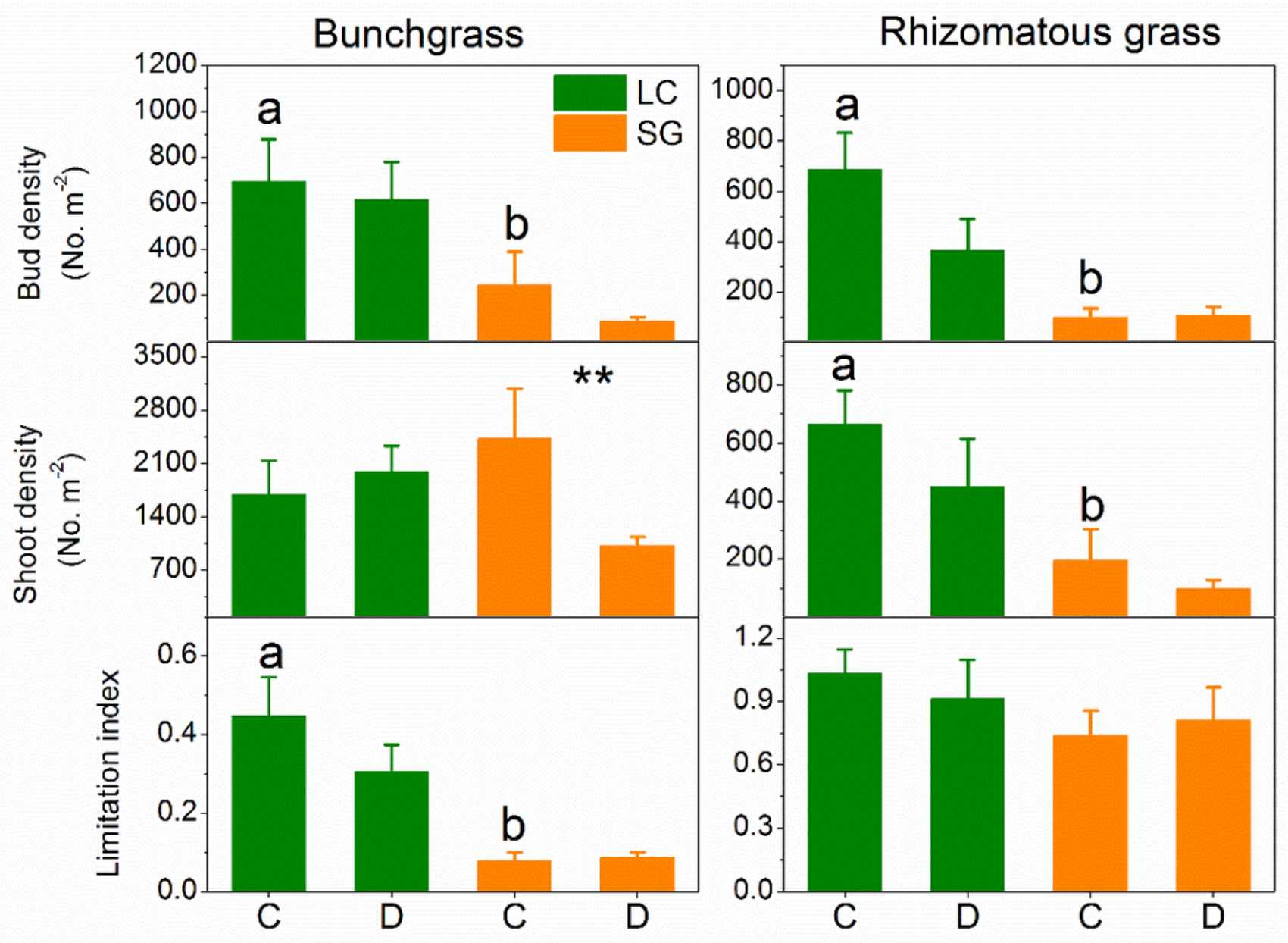

\section{Figure 2}

Effects of drought legacy and community type on belowground bud densities, aboveground shoot densities and the meristem limitation index (MLI) of two dominant growth forms (bunchgrass vs. rhizomatous grasses) in two grassland communities with different dominant species (LC, L. chinensis dominated community; SG, S. grandis dominated community). Each point represents the means with error bars indicating standard errors calculated from replicate plots for each treatment. Different letters indicate significant differences between the $L$. chinensis and $S$. grandis dominated at $P<0.05$. Statistical significance of drought legacy effect is depicted ${ }^{*} \mathrm{P}<0.1$ and ${ }^{* *} \mathrm{P}<0.05$. C, control (i.e., the ambient precipitation); D, recovery following the drought treatment (i.e., 4-year reduction of $66 \%$ growing season precipitation). 